\title{
Atualidades na assistência de enfermagem a portadores de úlcera venosa
}

\section{Nursing care to the venous ulcer carrier news}

\section{Atualidades en la ayuda del oficio de enfermera a los portadores de la úlcera del venosa}

\author{
Sara da Silva Carmo', Clarissa Domingos de Castro", Vanessa Souza Rios"', Micheline Garcia \\ Amorim Sarquis ${ }^{I V}$
}

\begin{abstract}
RESUMO
Úlcera venosa é uma lesão cutânea que acomete o terço inferior das pernas. Está associada à insuficiência venosa crônica, sendo esta a principal causa de úlcera de membros inferiores. Pode interferir na qualidade de vida, pois gera repercussões negativas na esfera social e econômica. A decisão quanto ao tipo do tratamento e orientações para prevenção de feridas exige conhecimento técnico e científico de um enfermeiro. É fundamental para esses profissionais atualizarem os conhecimentos sobre esse assunto, pois a construção de pesquisas é dinâmica e, constantemente, novos conhecimentos são incorporados ou descartados quando ultrapassados. Os objetivos deste artigo de atualização são discorrer sobre o histórico e sintomas da úlcera venosa, assistência de enfermagem, opções de tratamento, prevenção e relação custo/benefício do tratamento tradicional e atual de feridas. O diagnóstico baseia-se em história clínica completa, exame físico com identificação dos sinais e sintomas e exame complementar para analisar estrutura e função do sistema venoso. O tratamento é direcionado para obter cicatrização da úlcera e evitar recidivas. Os avanços no conhecimento sobre o tratamento de feridas têm permitido a integralidade do cuidado, busca pela autonomia do portador de úlcera venosa e ênfase na qualidade da assistência para favorecer a relação custo/benefício.
\end{abstract}

Palavras chave: Úlcera venosa; Assistência de Enfermagem; Cicatrização de feridas.

\section{ABSTRACT}

The Venous Ulcer is a cutaneous wound that appears in the inferior third of the legs. It is associated with the chronic venous insufficiency being it the main cause of ulcer in the inferior members. It can interfere in the quality of life because it causes negative repercussions in the social and economic spheres. The decision for the proper type of treatment and the orientations for the prevention of the wounds demands a nurse's technical and scientific knowledge. It is fundamental for these professionals to update their knowledge about the subject as the construction of researches is very dynamic and new information is constantly being incorporated or discarded when outdated. The objectives of this healthy updating article are to discuss through the history and the symptoms of the Venous Ulcer, nurse assistance, treatment options, prevention, and relation between cost and benefit of the traditional and current treatment of the wounds. The diagnosis is based on the complete clinical history, a physical exam identifying signals and symptoms, and a complementary exam to analyze the structure and function of the venous system. The treatment is directed to achieve complete healing of the ulcer and avoid future recurrences. The knowledge advances about the treatment of wounds have been permitted the integration of the care, the search for the autonomy of the bearer of Venous Ulcer, and the emphasis in the quality of assistance to benefit the relation between cost and benefit.

Key Words: Venous ulcer; Nursing Assistance; Wound cicatrization.

\footnotetext{
Acadêmica do 6으 período de Enfermagem do Centro Universitário Metodista Izabela Hendrix - Belo Horizonte MG. E-mail saragodsend@hotmail.com

"Acadêmica do 60 período de Enfermagem do Centro Universitário Metodista Izabela Hendrix - Belo Horizonte MG. E-mail: clarissaenfermagem@yahoo.com.br

III Acadêmica do 60 período de Enfermagem do Centro Universitário Metodista Izabela Hendrix - Belo Horizonte MG. E-mail: vanessa_srios@yahoo.com.br

iv Enfermeira. Docente da Disciplina Feridas e Ostomias do curso de Enfermagem e Coordenadora da Clínica de Enfermagem do Centro Universitário Metodista Izabela Hendrix. Referência em Tratamento e Prevenção de Lesão Cutânea da Prefeitura Municipal de Contagem - MG. Diretora Técnica da Socurativos - Clínica Especializada em Tratamento de Feridas e Ostomias. E-mail: micheline@socurativos.com.br
} 


\section{RESUMEN}

Úlcera venosa es una lesión cutánea que acomete el tercio inferior de las piernas y se asocian a la escasez venosa crónica, siendo esto la causa principal de la úlcera de miembros inferiores. Puede interferir con la calidad de la vida, ya que genera repercusiones negativas en la esfera social y económica. La decisión en cuanto al tipo de tratamiento y orientaciones para prevenir heridas exige un conocimiento técnico y científico de una enfermera. Es fundamental que estos profesionales actualicen el conocimiento en este tema, considerando que la construcción de la investigación es dinámica y, constantemente, nuevos conocimientos son incorporados o rechazados cuando son obsoletos. Los objetivos de este artículo de la actualización están al discurrir sobre el

\section{NTRODUÇÃO}

Úlcera de perna é a síndrome em que há destruição de estruturas cutâneas, tais como epiderme e derme, podendo afetar, também, tecidos mais profundos. Manifesta-se no terço inferior dos membros inferiores ${ }^{(1)}$.

A úlcera venosa representa cerca de $70 \%$ a $90 \%$ dos casos de úlceras de perna e apresenta como principal causa a insuficiência venosa crônica (2). Essa inadequação do funcionamento do sistema venoso é comum na população idosa, sendo a freqüência superior a $4 \%$ entre os idosos acima de 65 anos ${ }^{(3)}$.

O elevado número de recidivas das úlceras $(66 \%)$ constitui um dos problemas mais importantes na assistência à portadores de insuficiência venosa ${ }^{(4)}$. A educação do paciente, diante dessa situação, faz-se prioritário no cuidar em enfermagem.

Várias complicações decorrem da úlcera venosa, tais como as repercussões físicas, sociais, econômicas e emocionais que podem histórico y síntomas de la úlcera venosa, la asistencia de enfermera, opciones del tratamiento, prevención y relación costo/beneficio del tratamiento tradicional y actual de heridas. El diagnóstico se basa en la historia clínica completa, examen físico con la identificación de las señales y síntomas, y examen complementar para analizar la estructura y función del sistema venoso. El tratamiento es direccionado para obtener la cicatrización de la úlcera y evitar recidivas. Los avances en el conocimiento sobre tratamiento de heridas han permitido el completo cuidado, busca por la autonomía del portador de la úlcera venosa y énfasis en la calidad de asistencia para favorecer la relación costo/beneficio.

Palabras clave: Úlcera venosa; Asistencia de enfermera; Cicatrización de heridas.

interferir na qualidade de vida dos portadores dessa lesão cutânea ${ }^{(5)}$.

Durante a abordagem diagnóstica da úlcera venosa é essencial realizar uma avaliação global do paciente através da coleta de dados sobre a história clínica completa e exame físico ${ }^{(7)}$. A indicação do tratamento de feridas deve estar calcada nos princípios que acelerem a cicatrização, nos custos referentes à realização dos curativos, bem como na freqüência de troca dos mesmos. O custo do tratamento atualizado de feridas é menor quando comparado ao tradicional e o fator determinante para tal é o elevado número de trocas dos curativos no tratamento tradicional (8).

Por acometer grande parte da população brasileira, a úlcera de origem venosa constituise num problema epidemiológico que merece atenção especial por parte dos profissionais da área da saúde. De acordo com a deliberação 65/00 do Conselho Regional de Enfermagem Minas Gerais, de 22 de maio de 2005, a 
Carmo SS, Castro CD, Rios VS, Sarquis MGA. Atualidades na assistência de enfermagem a portadores de úlcera venosa. Revista Eletrônica de Enfermagem [serial on line] 2007 Mai-Ago; 9(2): 506-517. Available from: URL: http://www.fen.ufg. br/revista/v9/n2/v9n2a17.htm

decisão quanto ao tipo do tratamento a ser utilizado, bem como de orientações para prevenção de feridas exige conhecimento técnico e científico de um enfermeiro ${ }^{(9)}$. Sendo assim, é fundamental para essa categoria de profissionais atualizarem os conhecimentos sobre tal assunto, uma vez que a construção de pesquisas é dinâmica e, constantemente, novos conhecimentos são incorporados na prática clínica ou descartados quando ultrapassados ${ }^{(10)}$.

Neste sentido, os objetivos deste artigo de atualização são discorrer sobre o histórico e sintomas da úlcera venosa, assistência de enfermagem, opções de tratamento e prevenção dessa lesão cutânea, bem como a relação custo/benefício do tratamento tradicional e atual de feridas.

\section{Fisiopatologia da úlcera venosa}

A insuficiência venosa crônica é definida como "uma anormalidade do funcionamento do sistema venoso causada por uma incompetência valvular, associada ou não à obstrução do fluxo venoso. Pode afetar o sistema venoso superficial, o sistema venoso profundo ou ambos. Além disso, a disfunção venosa pode ser resultado de um distúrbio congênito ou pode ser adquirida" (11).

O resultado dessa disfunção no sistema venoso é a instalação de um estado de hipertensão venosa. Essa sobrecarga venosa ocorre devido à intensificação do fluxo sangüíneo retrógrado que sobrecarrega o músculo da panturrilha a ponto deste não conseguir bombear quantidades maiores de sangue, na tentativa de contrabalançar a insuficiência das válvulas venosas ${ }^{(11)}$.
A hipertensão venosa é responsável pelas alterações características da insuficiência venosa crônica ${ }^{(12)}$. São sinais clínicos dessa patologia: a presença de veias varicosas conseqüência da congestão do fluxo sanguíneo, decorrente da incompetência das válvulas venosas. As veias superficiais, principalmente as que possuem paredes mais delgadas, tornam-se dilatadas e tortuosas; edema de membros inferiores - a hipertensão venosa é alimentada durante o relaxamento muscular devido ao refluxo venoso, fato que impossibilita a pressão no interior do vaso sanguíneo atingir um valor abaixo de $60 \mathrm{mmHg}$ (13); hiperpigmentação da pele - caracterizada pela liberação de hemoglobina após o rompimento dos glóbulos vermelhos extravasados para o interstício, é degradada em hemossiderina, pigmento que confere a coloração castanhoazulada ou marrom-cinzentada aos tecidos ${ }^{(14)}$; dermatite venosa - cuja causa possível é de reação auto-imune desencadeada contra proteínas que extravasam para a hipoderme ou contra bactérias infectantes, manifestada através de eritema, edema, descamação e exsudato na extremidade do membro inferior, podendo apresentar prurido intenso (2); e finalmente, lipodermatoesclerose - que consiste no endurecimento da derme e tecido subcutâneo, decorrente da substituição gradual destes por fibrose ${ }^{(15)}$.

A patogênese da úlcera venosa ainda é obscura, porém existe um consenso de que a hipertensão venosa é a condição mais comum para o aparecimento dessa lesão ${ }^{(2)}$.

A formação da úlcera venosa pode estar associada ao acúmulo de líquido e o depósito de fibrina, que leva à formação de manguitos, no interstício interferindo negativamente na 
Carmo SS, Castro CD, Rios VS, Sarquis MGA. Atualidades na assistência de enfermagem a portadores de úlcera venosa. Revista Eletrônica de Enfermagem [serial on line] 2007 Mai-Ago; 9(2): 506-517. Available from: URL: http://www.fen.ufg. br/revista/v9/n2/v9n2a17.htm

nutrição dos tecidos superficiais. A deficiência no suprimento de oxigênio e nutrientes pode acarretar, nas regiões acometidas dos membros inferiores, em ulcerações e necroses. Outro mecanismo que elucida a úlcera venosa refere-se à reação entre os leucócitos e moléculas de adesão do endotélio havendo, conseqüentemente, liberação de citocina e radicais livres. Esse processo desencadeia inflamação que pode causar danos às válvulas venosas e ao tecido adjacente, aumentando a susceptibilidade a ulcerações ${ }^{(11)}$.

\section{Assistência de enfermagem}

Há algum tempo, o tratamento das lesões tissulares "deixou de ser apenas enfocado na realização da técnica de curativo, para incorporar toda a metodologia da assistência que o enfermeiro presta, com avaliação do estado geral do paciente, exame físico direcionado de acordo com a etiologia da lesão, escolha do tratamento e da cobertura a ser utilizada. Além do registro de enfermagem e projeção prognóstica" (16).

Os itens a serem analisados durante a avaliação do estado geral do paciente compreendem: higiene, estado nutricional, hidratação oral, sono/ repouso, eliminações, etilismo/ tabagismo, alergoses, patologias associadas, medicamentos em uso, idade, estresse, ansiedade, condições da pele ${ }^{(17)}$. O enfermeiro pode pesquisar o diagnóstico da úlcera venosa através da detecção de seus principais sinais e sintomas (Quadro 1 ).

Quadro 1: Histórico, Sinais e Sintomas da Úlcera Venosa.

\begin{tabular}{|c|c|}
\hline História & $\begin{array}{l}\text { - Imobilidade/obesidade/ocupação em pé/trauma. } \\
\text { - } \quad \text { Não há claudicação. Inchaço de tornozelo ou perna. } \\
\text { - } \quad \text { Desconforto moderado devido à úlcera - aliviado por elevação. } \\
\text { - História de Trombose venosa profunda ou veias varicosas. }\end{array}$ \\
\hline $\begin{array}{l}\text { Localização e } \\
\text { aparência da } \\
\text { úlcera }\end{array}$ & $\begin{array}{l}\text { - } \quad \text { Região ao redor do tornozelo em especial a área do maléolo medial. } \\
\text { - } \quad \text { Geralmente superficial com bordas irregulares. } \\
\text { - } \quad \text { Presença de tecido de granulação. Edema não depressível. } \\
\text { - É comum secreção intensa quando apresenta edema. }\end{array}$ \\
\hline $\begin{array}{c}\text { Outros } \\
\text { achados na } \\
\text { avaliação }\end{array}$ & $\begin{array}{l}\text { - Descoloração do tornozelo/parte inferior da perna (depósito de hemossiderina). Pode } \\
\text { - } \text { estar presente uma lipodermatoesclerose. } \\
\text { tornozelo. Índice de pressão tornozelo braço } 0,8 \text { a } 1,0 \text {. } \\
\text { - Dermatite venosa. Pulsos presentes. Ausência de déficit neurológico. } \\
\text { - Podem ser observadas cicatrizes de úlceras anteriores. }\end{array}$ \\
\hline
\end{tabular}

Fonte: Adaptado Sarquis MGA, et al., $2003^{(17)}$

Alguns exames complementares subsidiam o diagnóstico da úlcera venosa. O exame de escolha é o Duplex Scan. Tal exame propicia a visualização das alterações na estrutura e função no sistema venoso ${ }^{(3)}$.
Os exames de hemograma completo, glicemia em jejum, dosagem de albumina sérica, proteínas totais e fracionadas auxiliam no diagnóstico dos possíveis fatores que influenciam na cicatrização da ferida, bem 
Carmo SS, Castro CD, Rios VS, Sarquis MGA. Atualidades na assistência de enfermagem a portadores de úlcera venosa. Revista Eletrônica de Enfermagem [serial on line] 2007 Mai-Ago; 9(2): 506-517. Available from: URL: http://www.fen.ufg. br/revista/v9/n2/v9n2a17.htm

como de doenças associadas. A solicitação desses exames está regulamentada conforme a resolução 195 do Conselho Federal de Enfermagem - COFEN, podendo ser solicitado pelo enfermeiro ${ }^{(18)}$.

A partir do diagnóstico o enfermeiro constrói planos de cuidados cujos objetivos são proporcionar condições que minimizem o tempo de cicatrização da ferida, reduzem os riscos de infecções, prevenção de recidivas, garantam a segurança e conforto do paciente, dentre outros.

Cabe ao enfermeiro estabelecer comunicação terapêutica com o cliente visando à valorização das queixas apresentadas e o respeito à particularidade de cada indivíduo. Vale ressaltar a importância do enfermeiro usar comunicação verbal familiar à linguagem do paciente, para que o mesmo possa compreender as informações que thes são transmitidas e, assim, comprometer-se com sua saúde possibilitando o cumprimento das ações que Ihes são delegadas a fim de garantir o sucesso do tratamento.

O tratamento clínico oferecido ao portador de úlcera venosa consiste na realização do curativo, terapia compressiva, prescrição de dieta que favoreça a cicatrização, orientações quanto à importância de repouso e do uso de meias de compressão após a cura da ferida.

A finalidade da limpeza da ferida é a promoção de um ambiente favorável à cicatrização, através da remoção de fragmentos de tecido necrótico, debris, resíduos da cobertura anterior, excesso de exsudato, diminuição do número de microorganismos na lesão ${ }^{(2)}$. A técnica de limpeza aplicada deve atender aos princípios que otimizem o processo de cicatrização, tais como, reduzir as chances de traumas mecânicos e químicos no leito da ferida e manter a temperatura local em torno de $37^{\circ} \mathrm{C}$. Assim, a limpeza deve ser feita com soro fisiológico a 0,9\%, morno em jato para garantir limpeza eficaz e minimizar os riscos de trauma adicional na lesão ${ }^{(15)}$. O uso de anti-sépticos não é recomendado, pois os mesmos comprometem a reparação tecidual por serem citotóxicos aos fibroblastos, impedindo a granulação eficaz ${ }^{(19)}$.

Os tecidos necróticos que não foram eliminados da lesão cutânea através da limpeza podem ser retirados por meio do desbridamento autolítico ou mecânico (7). O desbridamento autolítico é promovido através da aplicação de coberturas primárias, pois estas conferem ambiente adequado para estimular a autodestruição tecidual. A autólise ocorre devido à atividade de enzimas lisossomais que quebram o tecido desvitalizado (3). O desbridamento autolítico pode ser utilizado em conjunto com outros ${ }^{(17)}$.

o desbridamento cirúrgico consiste na "remoção do tecido necrótico através da utilização de instrumental cirúrgico como bisturi, tesoura e outros. Este poderá ser utilizado para a remoção da necrose tipo escara (clinicamente apresentada como crosta preta endurecida), áreas de necrose extensas, e de necrose tipo esfacelo (clinicamente apresentada como tecido amarelo/esverdeado desvitalizado resultante da infecção bacteriana). É a técnica mais rápida e efetiva para a remoção da necrose, principalmente quando o paciente necessita de intervenção urgente, como nos casos em que há presença de celulite ou sepsis" (17). 
Carmo SS, Castro CD, Rios VS, Sarquis MGA. Atualidades na assistência de enfermagem a portadores de úlcera venosa. Revista Eletrônica de Enfermagem [serial on line] 2007 Mai-Ago; 9(2): 506-517. Available from: URL: http://www.fen.ufg. br/revista/v9/n2/v9n2a17.htm

A cobertura para a úlcera venosa deve absorver o exsudato do leito da lesão, manter ambiente local úmido, ser de fácil aplicação e remoção a fim de evitar traumas durante a troca, minimizar a dor da ferida, ser hipoalergênica, ser impermeável a patógenos, ser estéril e livre de contaminantes, bem como prover isolamento térmico. A escolha da cobertura será efetivada após avaliação dos aspectos e localização da lesão cutânea, exigências e escolhas do paciente, bem como da diversidade e características dos produtos disponíveis ${ }^{(2)}$. Com base na leitura dos artigos $(2,4,15)$ foi possível elaborar o Quadro 2 que mostra os componentes, indicação de coberturas utilizadas no tratamento de feridas.

Quadro 2: Coberturas

\begin{tabular}{|c|c|c|c|}
\hline & Componentes & Indicação & Observação \\
\hline Hidrocolóide & $\begin{array}{l}\text { Pectinas, carboximetilcelulose } \\
\text { sódica e gelatina revestida por } \\
\text { camada de poliuretano, partícula } \\
\text { de alginato de cálcio. }\end{array}$ & $\begin{array}{l}\text { Feridas com pouco a } \\
\text { moderado exsudato. }\end{array}$ & $\begin{array}{l}\text { Pode ser associado ao } \\
\text { hidrocolóide em pó ou em pasta } \\
\text { em úlceras com profundidade, } \\
\text { para aumentar capacidade de } \\
\text { absorção. }\end{array}$ \\
\hline $\begin{array}{l}\text { Alginato de } \\
\text { cálcio }\end{array}$ & $\begin{array}{c}\text { Fibras naturais de alginato de } \\
\text { cálcio e sódio, derivados de algas } \\
\text { marinhas marrons. }\end{array}$ & $\begin{array}{l}\text { Feridas com moderado } \\
\text { a muito exsudato. }\end{array}$ & $\begin{array}{l}\text { Auxilia o desbridamento } \\
\text { autolítico, faz hemostase. }\end{array}$ \\
\hline Hidrogel & $\begin{array}{c}\text { Carboximetilcelulose e propileno- } \\
\text { glicol, partícula de alginato de } \\
\text { cálcio. }\end{array}$ & Feridas com necrose. & Desbridamento autolítico. \\
\hline $\begin{array}{l}\text { Espuma de } \\
\text { poliuretano } \\
\text { com prata }\end{array}$ & $\begin{array}{l}\text { Almofada de espuma de camadas } \\
\text { sobrepostas de não-tecido e } \\
\text { hidropolímero, revestida por } \\
\text { poliuretano e prata. }\end{array}$ & $\begin{array}{l}\text { Feridas com moderada } \\
\text { a alta exsudação, } \\
\text { infectada e/ou } \\
\text { estagnadas. }\end{array}$ & $\begin{array}{l}\text { Absorve o exsudato, trata a } \\
\text { infecção e estimula o } \\
\text { desbridamento autolítico. }\end{array}$ \\
\hline $\begin{array}{l}\text { Carvão } \\
\text { ativado }\end{array}$ & $\begin{array}{c}\text { Partículas de carvão impregnadas } \\
\text { com íons de prata. }\end{array}$ & $\begin{array}{l}\text { Feridas infectadas ou } \\
\text { não que drena } \\
\text { moderado ou } \\
\text { abundante exsudato. }\end{array}$ & $\begin{array}{c}\text { Não deve ser recortado. Têm } \\
\text { ação bactericida da prata e } \\
\text { elimina odores desagradáveis, } \\
\text { pois tem capacidade de filtrá-los. }\end{array}$ \\
\hline
\end{tabular}

A reparação tecidual é influenciada expressivamente pelo estado nutricional do portador de lesão, pois os mecanismos fisiológicos efetivados nesse processo demandam grandes quantidades de proteínas, minerais, vitaminas e calorias (15). O profissional de saúde deve identificar os déficits nutricionais do portador de úlcera de estase e adequar os alimentos prescritos às possibilidades financeiras (12), bem como avaliar a patologia de base desse paciente como, por exemplo, diabetes mellitus, obesidade e hipertensão a fim de planejar adequadamente a assistência ${ }^{(15)}$. Com base na leitura do artigo ${ }^{(15)}$ foi construído o Quadro 3 que mostra a fonte de alimentos e função dos nutrientes necessários à cicatrização. 
Carmo SS, Castro CD, Rios VS, Sarquis MGA. Atualidades na assistência de enfermagem a portadores de úlcera venosa. Revista Eletrônica de Enfermagem [serial on line] 2007 Mai-Ago; 9(2): 506-517. Available from: URL: http://www.fen.ufg. br/revista/v9/n2/v9n2a17.htm

Quadro 3: Fonte de alimentos e função dos nutrientes necessários à cicatrização

\begin{tabular}{|c|c|c|}
\hline Nutrientes & Fonte de alimentos & Função dos nutrientes na cicatrização \\
\hline Vitamina A & $\begin{array}{l}\text { Vegetais folhosos verde- } \\
\text { escuros, vegetais e frutas } \\
\text { amarelo-laranja. }\end{array}$ & $\begin{array}{c}\text { Contribui para a epitelização e produção de } \\
\text { colágeno. Diminui os riscos de infecção, pois } \\
\text { bloqueia os efeitos inibidores dos glicocorticóides } \\
\text { no processo de construção tecidual. }\end{array}$ \\
\hline Vitamina $\mathbf{B}_{6}$ & $\begin{array}{l}\text { Frutas não cítricas (banana), } \\
\text { tubérculos, carnes, fígado } \\
\text { bovino. }\end{array}$ & Eleva a produção de proteínas. \\
\hline Vitamina C & $\begin{array}{l}\text { Frutas cítricas, tomate, couve- } \\
\text { flor, brócolis, cenoura, batatas, } \\
\text { repolho. }\end{array}$ & $\begin{array}{c}\text { Coenzima das hidroxilases na produção de } \\
\text { colágeno. }\end{array}$ \\
\hline Vitamina $\mathrm{K}$ & $\begin{array}{l}\text { Vegetais folhosos verde- } \\
\text { escuros, fígado bovino, óleos } \\
\text { vegetais. }\end{array}$ & $\begin{array}{c}\text { Coenzima necessária na produção do precursor dos } \\
\text { fatores de coagulação. }\end{array}$ \\
\hline Proteína & $\begin{array}{l}\text { Carnes vermelhas, frango, } \\
\text { peixe. }\end{array}$ & Bloco de construção tecidual. \\
\hline Colágeno & Gelatina, pé de galinha. & Faz parte da constituição tecidual. \\
\hline Albumina & Clara de ovo, albumina em pó. & $\begin{array}{l}\text { A albumina sérica é um indicador do estado } \\
\text { nutricional do cliente. Baixos níveis de albumina } \\
\text { estão associados à cicatrização deficiente. }\end{array}$ \\
\hline Zinco & $\begin{array}{l}\text { Peixe, carne escura, ovos, } \\
\text { legumes. }\end{array}$ & Crescimento e multiplicação celular. \\
\hline Ferro & $\begin{array}{l}\text { Feijão preto, brócolis, açaí, } \\
\text { laranja seleta, aveia (flocos } \\
\text { crus), espinafre cru, soja crua. }\end{array}$ & $\begin{array}{c}\text { Faz parte da constituição da hemoglobina cuja } \\
\text { função é o transporte de oxigênio que é necessário } \\
\text { para o processo de cicatrização. }\end{array}$ \\
\hline Calorias & & Suprimento energético da célula. \\
\hline
\end{tabular}

A terapia compressiva pode ser realizada com o uso de meias de compressão ou bandagens, sendo fundamental para que o tratamento da úlcera venosa seja eficaz, pois constitui medida de controle da hipertensão venosa. A intensidade da compressão externa aplicada nos membros inferiores deve decrescer no sentido tornozelo para o joelho, a fim de reverter o efeito produzido pelo ortorstatismo prolongado: aumento da pressão hidrostática intravascular ${ }^{(20)}$.
A Bota de Unna constitui uma das formas de terapia compressiva inelástica (4). A troca dessa bandagem deve ser realizada uma ou duas vezes por semana, dependendo do volume de exsudato e do edema, e que tal procedimento pode ser feito por um enfermeiro, médico ou um membro familiar capacitado ${ }^{(2)}$. Para este tipo de compressão é necessário que a ferida esteja instalada, pois após sua cura o paciente deve usar a meia de compressão com o intuito de evitar recidiva ${ }^{(4)}$. 
Carmo SS, Castro CD, Rios VS, Sarquis MGA. Atualidades na assistência de enfermagem a portadores de úlcera venosa. Revista Eletrônica de Enfermagem [serial on line] 2007 Mai-Ago; 9(2): 506-517. Available from: URL: http://www.fen.ufg. br/revista/v9/n2/v9n2a17.htm

O repouso consiste na elevação dos membros inferiores, várias vezes ao dia, possibilitando assim a regressão do edema de tornozelo e/ou perna, característico da insuficiência venosa crônica, além de amenizar a dor nos membros inferiores. Cabe ressaltar que os membros inferiores devem ser posicionados na altura do coração ${ }^{(12)}$.

O principal motivo das recidivas é a negligência do paciente em relação às medidas preventivas, tal como o uso de meias de compressão. Esta atitude do cliente advém, na maioria dos casos, do desconhecimento sobre a importância dessas técnicas na prevenção dos efeitos da insuficiência venosa. Logo, o profissional de saúde deve fazer as orientações necessárias ao paciente, bem como esclarecer a este todas as dúvidas apresentadas. Pois, a melhor compreensão da relevância da meia de compressão na doença venosa possibilita ao paciente adesão ao tratamento efetivo e, possivelmente, "o autocuidado e a auto-ajuda, integrantes desse compromisso individual, promovem melhorias significativas na qualidade de vida das pessoas portadoras de qualquer enfermidade, diminuindo os casos recidivantes" (12).

Os efeitos produzidos pela compressão elástica consistem na redução do diâmetro do vaso permitindo, assim, maior proximidade dos folhetos das válvulas a fim de minimizar o refluxo; aumentar velocidade do fluxo venoso, propiciando reabsorção do excesso de liquido no interstício e aumento da função da bomba muscular ${ }^{(9)}$.

A mensuração dos membros inferiores é conduta necessária para a escolha adequada da meia de compressão, devendo ser medidas a circunferência do tornozelo e da panturrilha, bem como a altura entre a base do calcanhar e região abaixo do joelho. Nos casos em que seja necessário prescrever meias que se estendem até a coxa (por exemplo, quando presente edema acima ou abaixo do joelho e deformidades nas articulações) devem ser medidos, também, o diâmetro da coxa no seu ponto mais largo e a altura entre a base do calcanhar e dobra glútea. A determinação de tais medidas deve ser feita na parte da manhã, logo depois do paciente acordar, ou depois de retirar a bandagem de compressão ${ }^{(2)}$.

As meias de compressão devem ser aplicadas pela manhã antes do paciente deambular e removidas antes de se deitar. Os portadores de doença venosa devem usar as meias de descanso por toda a vida, uma vez que estas mantêm $o$ tratamento da insuficiência venosa somente quando usadas assiduamente ${ }^{(4)}$. 
Carmo SS, Castro CD, Rios VS, Sarquis MGA. Atualidades na assistência de enfermagem a portadores de úlcera venosa. Revista Eletrônica de Enfermagem [serial on line] 2007 Mai-Ago; 9(2): 506-517. Available from: URL: http://www.fen.ufg. br/revista/v9/n2/v9n2a17.htm

Quadro 4: Pressões recomendadas para o tratamento das desordens venosas

\begin{tabular}{|c|c|c|c|}
\hline Classe & Pressão no tornozelo & Suporte & I ndicações clínicas \\
\hline I & $14-17 \mathrm{mmHg}$ & Leve & Tratar veias varicosas, edema moderado. \\
\hline II & $18-24 \mathrm{mmHg}$ & Médio & $\begin{array}{c}\text { Tratar veias varicosas mais severas e prevenir úlcera } \\
\text { I I I }\end{array}$ \\
\hline
\end{tabular}

Fonte: Borges EL. Tratamento tópico de úlcera venosa: proposta de uma diretriz baseada em evidências. [Doutorado]. Ribeirão Preto (SP): Escola de Enfermagem/USP; $2005^{(2)}$.

\section{Qualidade de vida de portadores de úlcera venosa}

As úlceras venosas "causam danos aos pacientes porque afetam seu estilo de vida devido à dor, depressão, perda da auto-estima, isolamento social, inabilidade para o trabalho e, freqüentemente, hospitalizações ou visitas clínicas ambulatoriais" (2). Para muitos pacientes, a úlcera venosa significa isolamento social, efeito emocional negativo por desencadear ao indivíduo constrangimento, tristeza, raiva, auto-imagem negativa ${ }^{(6)}$.

Entretanto, em um estudo realizado com 89 pessoas, no período de setembro de 2000 a março de 20001, obteve-se resultado diferente em relação à qualidade de vida de portadores de úlcera venosa crônica. Dos participantes da pesquisa, $37(41,7 \%)$ e $35 \quad(39,31 \%)$ apresentaram, respectivamente, qualidade de vida considerada como "muito boa" e "boa". As divergências no tocante à qualidade de vida de pessoas com úlcera venosa crônica resultam de que a qualidade de vida é marcada pela subjetividade e multidimensionalidade e, portanto, a avaliação da mesma dependerá dos valores e concepções do indivíduo, bem como dos contextos diferenciados nos quais as pessoas estão inseridas ${ }^{(6)}$.

\section{Comparação,}

custo/ benefício, tradicional e tratamento atual de feridas

O custo da limpeza e tratamento atualizado é inferior ao custo final dos curativos tradicionais. $\mathrm{O}$ tratamento atual proporciona maior conforto para o paciente devido o menor número de trocas de curativos realizados, além de acelerar o processo de cicatrização, tornando o tratamento menos oneroso (7). Com a finalidade de ilustrar tal fato, é abordada a comparação entre tratamento tradicional e atual de feridas de duas pacientes com úlcera venosa atendidas na Clínica Escola de Enfermagem do Centro Universitário Metodista Izabela Hendrix, Belo Horizonte - Minas Gerais.

O cálculo dos custos dos curativos foi feito com base nas feridas descritas adiante, considerando produtos utilizados para a troca diária de curativo em tratamento tradicional e os curativos realizados com coberturas de última geração (Quadro 5). Vale ressaltar que no tratamento tradicional é feita troca de curativo diariamente e no tratamento atualizado, geralmente, as trocas são realizadas duas vezes por semana.

Quadro 5: Relação de alguns produtos usados no tratamento tradicional e atual de feridas 
Carmo SS, Castro CD, Rios VS, Sarquis MGA. Atualidades na assistência de enfermagem a portadores de úlcera venosa. Revista Eletrônica de Enfermagem [serial on line] 2007 Mai-Ago; 9(2): 506-517. Available from: URL: http://www.fen.ufg. br/revista/v9/n2/v9n2a17.htm

\begin{tabular}{|c|c|c|c|}
\hline $\begin{array}{c}\text { Tipo de } \\
\text { tratamento }\end{array}$ & Material para limpeza & $\begin{array}{l}\text { Produto } \\
\text { utilizado }\end{array}$ & $\begin{array}{c}\text { Material para troca diária de curativo + } \\
\text { limpeza diária }\end{array}$ \\
\hline \multirow[b]{2}{*}{$\begin{array}{l}\text { Tratamento } \\
\text { tradicional }\end{array}$} & \multirow{2}{*}{$\begin{array}{l}\text { Solução Fisiológica 0,9\% (250 } \\
\text { ml); PVPI tópico ( } 20 \mathrm{ml} \text { ); PVPI } \\
\text { degermante ( } 20 \mathrm{ml} \text { ); Luva } \\
\text { procedimento (par); Gase ( } 3 \\
\text { embalagens); Agulha } 25 \times 8 \mathrm{~mm} \text {. } \\
\text { Custo: } \mathrm{R} \$ 4,45\end{array}$} & $\begin{array}{l}\text { Colagenase } \\
10 \%, 30 \mathrm{grs} .\end{array}$ & $\begin{array}{c}\text { Colagenase } 5 g r s \text { ao dia; atadura; } \\
\text { esparadrapo } 20 \mathrm{~cm} \text {; gase ( } 2 \text { embalagens). } \\
\text { Custo: } \operatorname{R} \$ 11,78\end{array}$ \\
\hline & & $\begin{array}{l}\text { Sulfadiazina de } \\
\text { prata, 30grs. }\end{array}$ & $\begin{array}{l}\text { Sulfadiazina de prata } 5 \mathrm{grs} \text { ao dia; atadura } \\
\qquad \begin{array}{c}15 \mathrm{~cm} \text {; esparadrapo } 20 \mathrm{~cm} \text {; gase ( } 2 \\
\text { embalagens). } \\
\text { Custo: } \mathrm{R} \$ 11,46\end{array}\end{array}$ \\
\hline \multirow{2}{*}{$\begin{array}{l}\text { Tratamento } \\
\text { atual }\end{array}$} & \multirow{2}{*}{$\begin{array}{l}\text { Solução Fisiológica 0,9\% ( } 250 \\
\text { ml); Gase ( } 1 \text { embalagem.); } \\
\text { Agulha } 25 \times 8 \text { mm; Luva } \\
\text { procedimento (par). } \\
\text { Custo: } \operatorname{R} \$ 2,05\end{array}$} & Hidrogel 80grs. & $\begin{array}{c}\text { Hidrogel } 5 \text { grs ao dia; atadura } 15 \mathrm{~cm} \text {; } \\
\text { esparadrapo } 20 \mathrm{~cm} \text {; gase ( } 2 \text { embalagens). } \\
\text { Custo: } \operatorname{R} \$ 9,90\end{array}$ \\
\hline & & $\begin{array}{l}\text { Alginato de } \\
\text { cálcio e sódio } \\
\text { placa } 10 \times 10 .\end{array}$ & $\begin{array}{l}\text { Alginato de cálcio e sódio placa } 10 \times 10 ; \\
\text { atadura } 15 \mathrm{~cm} \text {; esparadrapo } 20 \mathrm{~cm} \text {. } \\
\text { Custo: } \mathrm{R} \$ 30,61\end{array}$ \\
\hline
\end{tabular}

Paciente L.M.S. portadora de duas lesões crônicas, existentes há três anos, resultantes de insuficiência venosa do membro inferior direito, comprometidas por tecido necrótico tipo esfacelo, drenando quantidade moderada de exsudato. Uma ferida apresentava $2,0 \mathrm{~cm}^{2}$ de área e a outra $2,3 \mathrm{~cm}^{2}$ de área. A paciente relatou que em tratamentos anteriores usou sulfadiazina de prata e colagenase. Nestes tratamentos tradicionais a paciente gastou em média, durante o tratamento com sulfadiazina de prata, $\mathrm{R} \$ 80,22$ por semana, totalizando $\mathrm{R} \$ 320,88$ de gastos mensalmente. Anualmente os custos referentes ao tratamento com sulfadiazina de prata foram de $\mathrm{R} \$ 3.850,56$. Já os custos do tratamento com colagenase foram $R \$ 82,46$ e $R \$ 329,84$ e $R \$ 3.958,08$, respectivamente, por semana, mês e ano. A paciente, referida anteriormente, teve início com o tratamento atualizado de feridas, na Clínica Escola, no dia 30/11/05 e recebeu alta no dia 15/03/06. O tratamento consistiu, basicamente, no uso de alginato de cálcio e sódio e a bota de unna. O custo total semanal foi de $R \$ 57,10$. Os gastos totais referentes ao mês foram de $R \$ 228,40$. O custo total do tratamento atualizado, com cura após três meses e 15 dias, foi de $R \$ 799,40$.

Paciente S.A.A. portadora de duas lesões crônicas causadas por insuficiência venosa do membro inferior direito (MID) e membro inferior esquerdo (MIE) comprometidas por tecido necrótico tipo esfacelo, odor acentuado, drenando muito exsudato de aspecto seroso. $O$ tempo de existência das feridas do MID e MIE foram de, respectivamente, 7 anos e 11 anos. A dimensão da lesão do MID era $2,5 \mathrm{~cm}$ verticalmente e $3,0 \mathrm{~cm}$ horizontalmente e o MIE apresentava várias lesões. Segundo a paciente em tratamentos anteriores usou sulfadiazina de prata e colagenase. Nestes tratamentos tradicionais a paciente gastou em média, durante o tratamento com sulfadiazina de prata, $\mathrm{R} \$ 160,44$ por semana, totalizando $\mathrm{R} \$ 641,76$ de gastos mensalmente. Já os custos do tratamento com colagenase foram $\mathrm{R} \$ 164,92$ e $\mathrm{R} \$ 659$, 68, respectivamente, por 
Carmo SS, Castro CD, Rios VS, Sarquis MGA. Atualidades na assistência de enfermagem a portadores de úlcera venosa. Revista Eletrônica de Enfermagem [serial on line] 2007 Mai-Ago; 9(2): 506-517. Available from: URL: http://www.fen.ufg.br/revista/v9/n2/v9n2a17.htm

semana e por mês. Os custos anualmente foram de $\mathrm{R} \$ 7.916,16$.

A paciente, referida anteriormente, teve início com o tratamento atualizado de feridas, na Clínica Escola, no dia 03/04/06 e recebeu alta no dia 20/06/06. Neste tratamento foram utilizados o hidrogel, espuma com prata e bota de unna. O custo total semanal foi de $\mathrm{R} \$ 118,60$. Os gastos totais referentes ao mês foram de $\mathrm{R} \$ 474,40$. O custo total do tratamento atualizado, com cura após dois meses e dezessete dias, foi de $\mathrm{R} \$ 1.186$ referentes ao tratamento das lesões cutâneas existentes nos dois membros inferiores.

\section{CONSI DERAÇÕES FI NAIS}

A prática clínica é uma importante fonte de inovação. É perceptível o avanço na produção dos conhecimentos sobre o tratamento ao portador de feridas crônicas. Tal prática em saúde envolve atualmente o princípio da integralidade em detrimento de uma abordagem curativa centrada na técnica, bem como preza a busca pela autonomia do portador de úlcera venosa, uma vez que o paciente ocupa o papel principal no controle da hipertensão venosa e no processo de cicatrização dessa lesão cutânea. Além disso, o empenho para a diminuição de custos está começando a enfatizar a qualidade da assistência, uma vez que um produto de baixo custo pode tornar o tratamento de feridas oneroso se não proporcionar os resultados desejados.

\section{REFERÊNCIAS}

1. Frade MAC, Cursi IB, Andrade FF, Soares SC, Ribeiro WS, Santos SV, et al. Úlcera de perna: um estudo de casos em Juiz de Fora-MG
(Brasil) e região. Anais Brasileiros de Dermatologia 2005 jan-fev; 80 (1).

2. Borges EL. Tratamento tópico de úlcera venosa: proposta de uma diretriz baseada em evidências. [Doutorado]. Ribeirão Preto (SP): Escola de Enfermagem/USP; 2005.

3. Abbade LPF, Lastória S. Abordagem de pacientes com úlcera de perna de etiologia venosa. Anais Brasileiros de Dermatologia. [serial on line] 2006 Dez [cited 2007 Mar 31]; 81(6): 509-522. Available from URL: http://www. scielo.br/pdf/abd/v81n6/v81n06a0 2.pdf

4. Lopez AR, Aravites LB, Lopes MR. Úlcera venosa. Acta Médica Porto Alegre 2005; 26: 331-341.

5. Junior OL, Buzatto SHG, Fontes OA, Miyazaki COM, Godoy JMP. Qualidade de vida em pacientes com lesões ulceradas crônicas na insuficiência venosa de membros inferiores. Cirurgia Vascular Angiologia 2001 fev; 17 (1): 15-20.

6. Yamada BFA. Qualidade de vida de pessoas com úlceras venosas crônicas. [Dissertação]. Ribeirão Preto (SP): Escola de Enfermagem/USP; 2001.

7. Aguiar ET, Pinto LJ, Figueiredo MA, Savino NS. Úlcera de Insuficiência Venosa Crônica. J ornal Vascular Brasileiro 2005 jul; 4 (2): 195200.

8. Sarquis MGA. Custos de Tratamentos de Feridas [online] 2005 Available from URL: http: / www. socurativos.com.br

9. COREN - MG. Deliberação no $65 / 00$ de 22 de maio de 2000. Belo Horizonte.

10. Ferreira AM, Andrade D. Swab de feridas: recomendável? Revista de Enfermagem UERJ 2006 jul/set; 14 (3): 440-446.

11. França LHG, Tavares V. Insuficiência venosa crônica: uma atualização. Sociedade Brasileira de Angiologia e Cirurgia Vascular 2003; 2 (4): 318-328.

12. Silva JLA, Lopes MJ M. Educação em saúde a portadores de úlcera varicosa através de atividades de grupo. Revista Gaúcha de Enfermagem 2006 jun; 27 (2): 240-250.

13. Pires EJ. Fisioterapia na cicatrização e recuperação funcional nos portadores de úlcera de hipertensão venosa crônica: uso da estimulação elétrica com corrente de alta voltagem. [Dissertação]. São Paulo (SP): Faculdade de Medicina/USP; 2005.

14. Bersusa AAS, Lages JS. Integridade da pele prejudicada: identificando e diferenciando uma úlcera arterial e uma venosa. Ciência, cuidado e saúde 2004 jan-abr; 3(1):81-92.

15. Poletti NAA. O cuidado de enfermagem a pacientes com feridas crônicas. A busca de 
Carmo SS, Castro CD, Rios VS, Sarquis MGA. Atualidades na assistência de enfermagem a portadores de úlcera venosa. Revista Eletrônica de Enfermagem [serial on line] 2007 Mai-Ago; 9(2): 506-517. Available from: URL: http://www.fen.ufg. br/revista/v9/n2/v9n2a17.htm

evidências para a prática. [Dissertação].

Ribeirão Preto (SP): Escola de

Enfermagem/USP; 2000.

16. Oliveira BGRB, Castro JBA, Andrade NC.

Técnicas para avaliação do processo cicatricial de feridas. Revista Nursing 2006 nov; 102(9): 1106-1110.

17. Sarquis MGA, et al. Manual de tratamento e prevenção de lesões cutâneas. 2o ed. Contagem, 2003.

18. Conselho Federal de Enfermagem. Resolução COFEN-195/1997 [on line]. [cited 2006 May 21] Available from URL: http://www.coren-

df.org. br/site/materias. asp?Articlesl $D=710$.

19. Écheli CSB, Busato CR. Tratamento tópico de úlcera de estase venosa - proposta para padronização. Ciência, Biologia e Saúde 2006 mar; 12(1): 7-14.

20. Moraes MRS, Silva JCCB. Insuficiência venosa crônica dos membros inferiores. Revista da Sociedade Brasileira de Clínica Médica 2004; 2 (4): 113-118.

Artigo recebido em 19.10.06

Aprovado para publicação em 27.08.07 